\title{
Exploring the Pedagogical Effectiveness of Clickers
}

\author{
Robin K. Morgan, PhD \\ Professor, Department of Psychology \\ Indiana University Southeast
}

Clickers, electronic response systems, are widely popular in college classrooms and proponents have argued clickers can increase student engagement, active learning, and, perhaps most importantly, student comprehension. Determining whether the effectiveness of clickers justified their purchase seemed warranted. A campus-wide project was developed to address this question. Five university instructors adopted clickers in one of their introductory courses (psychology, speech, accounting, and education) while teaching a second, control course. Contrary to expectation, attrition was higher and grades were lower in the clicker courses, although these differences were not statistically significant.

Over the past 20 years, the technology used on university campuses has expanded from overhead projectors and videotapes to comprehensive multi-media presentations involving laptops, LCD projectors, online testing, and personal response systems or clickers (MacGeorge, et al., 2008; Stowell \& Nelson, 2007). Researchers report that instructors may use the novel technological capabilities of clickers to enhance questioning and feedback (Trees \& Jackson, 2007); to motivate and monitor the participation of each of their students (Stowell \& Nelson, 2007); to foster discussions of important concepts (Brickman, 2006); and to energize and activate students' thinking (Collins, Moore, \& Shaw-Kokot, 2007). Bransford and colleagues cite clicker technology and the related pedagogy as one of the most promising methods for transforming classrooms to be more learner-, knowledge-, assessment-, and community-centered (Bransford, Brophy, \& Williams, 2000).

In addition, students appear to favor electronic response systems over traditional lecture formats. Judson and Sawada (2002), in a review of the literature on clicker use, noted that students find clickers to be helpful in comprehension, and cited some (although limited) evidence for benefits in academic achievement. In a study of clicker use in biology classes, Brewer (2004) found that the use of clickers allowed instructors to receive feedback that helped them appropriately set the pace of the course. Clickers can also enhance reflection and understanding when used with small group discussion (Brewer, 2004; Brickman, 2006). Likewise, Draper and Brown (2004), in a multi-disciplinary study of clicker use, note several advantages of clickers (lectures are more fun, anonymity allows students to answer without the risk of embarrassment, students can check their understanding of the material).

However, students and instructors both have cited some possible disadvantages of clicker use (clickers can distract from learning, focus seems to be on technology rather than the material, questions are not very helpful). Carnaghan and Webb (2007), for example, found that student engagement declined when clickers were introduced into their courses. Although students reported enjoying the use of the clickers, this satisfaction did not translate into increased satisfaction with the course. Additionally, strong evidence for increases in test scores and/or course grades associated with the use of clickers is minimal as yet (Draper \& Brown, 2004; Judson \& Sawada, 2002). The research to date seems to suggest it is how the instructor makes use of the clickers, rather than the simple adoption of clickers themselves, that determines their pedagogical effectiveness.

The research to date seems to suggest it is how the instructor makes use of the clickers, rather than the simple adoption of clickers themselves, that determines their pedagogical effectiveness.

Reviewing the literature on clickers suggested that the most positive results of clickers were posited to occur in relatively large classes where one-on-one interaction between students and professors may not be feasible. Draper and Brown 
(2004), for example, assessed the student response to clickers in fifteen classes ranging in size from 18 students to close to 500 students. They argued that clickers allowed increased interactivity during lectures and that even students in the smallest classes appreciated the increased anonymity afforded by the use of clickers. More recently, Morling, McAuliffe, Cohen and DiLorenzo (2008) assessed the efficacy of clickers in four large sections of introductory psychology, with approximately 350 students per section. These researchers reported that clickers led to a small, positive effect on exam scores. However, students in the clicker classes in this study did not report feeling any more engaged during class than did students in the non-clicker classes.

As these results have become more well-known, the faculty on our campus began to consider using clickers in their classes. Our teaching and learning center began to receive requests to provide workshops on the use of clickers and, individually, several faculty members began contacting publishers about the possibility of adopting clickers. It appeared that we were on the 'fast track' to adopting this new technology.

The primary mission of our university is teaching and, as a result, we have maintained an average class size of
Although familiar with the rationale behind the scholarship of teaching and learning, many faculty on our campus were less comfortable in attempting to assess whether clickers increased student learning. approximately 25 students. Prior to asking students to purchase clickers for their classes, we wanted to determine if this technology would be pedagogically effective, given our small class size. Although familiar with the rationale behind the scholarship of teaching and learning, many faculty on our campus were less comfortable in attempting to assess whether clickers increased student learning. Therefore, with the help of our teaching and learning center, five introductory courses were selected to introduce and evaluate the use of clickers. The goal of this research was to identify whether the addition of clickers would improve retention rates, grades, and student satisfaction. Five instructors each taught two sections of their respective introductory course, one section using a standard lecture format, the other incorporating personal response systems. The course objectives, materials, and grading practices were identical for each section the instructor taught. It was expected that the sections using clickers would have lower attrition levels, higher grades, and greater satisfaction with technology use.

\section{Method}

\section{Participants}

Five full-time residential faculty members (one full professor, two associate professors, one assistant professor, and one senior lecturer) were the instructors for the selected courses. Students in ten sections of introductory courses (four sections of psychology, two sections of accounting, two sections of education, and two sections of speech) agreed to participate in this study, which had been approved by the university's Institutional Review Board (IRB). No course credit or other benefits were provided for participation. Enrollment in both the control and clicker classes varied from approximately 20 students per course to approximately 50 students per course, with the average enrollment being 30 students for the control classes and 29.2 students for the clicker classes. Overall, 146 students participated in the clicker classes and 150 students in the control classes. Despite this across-instructor disparity, each instructor's clicker and control conditions were quite similar (see Table 1). Mean age and gender breakdown were fairly consistent and representative of the campus. Overall, $70 \%$ of students were in their first year of college, $18 \%$ were sophomores, and $2 \%$ were juniors. No differences in class rank were found 
between control and clicker classes. In addition, no differences in high school rank or SAT scores were found between the classes.

Table 1: Demographics of Students in Control and Clicker Classes

\begin{tabular}{|l|c|c|c|}
\hline & Mean Age & Percent Females & Percent Males \\
\hline Clicker & 21.7 & $66 \%$ & $34 \%$ \\
\hline Control & 21.3 & $73 \%$ & $27 \%$ \\
\hline
\end{tabular}

\section{Materials}

Instructors used their standard lecture format for both the clicker and the control classes. All assignments, exams, readings, and material covered were as similar as possible in both the clicker and the control condition for each instructor. For the clicker classes, students were asked to purchase from the university bookstore the university supported clicker, the eInstruction CPS radio frequency electronic response remote. This remote allows students to enter either numbers or letters for multiple-choice, true-false, or instructor-created questions. Each instructor created his or her own questions for use with the clickers. Instructors attended a week-long training session sponsored by the campus teaching and learning center, during which they were taught how to use the clickers and practiced creating questions that would focus on building conceptual understanding and opportunities for discussion, rather than simply reflecting memorized items. In addition, instructors were informed of the design methodology being used to evaluate clickers in the present study.

At the end of the semester, all students completed a course survey measuring study habits and attitudes toward the class. Questions included items such as how much time students studied outside of class, how much time students spent preparing for the class, whether students actively participated in class, and whether the instructor's use of new technology promoted learning in the course or created anxiety for the student. Each of the five instructors completed a similar questionnaire to assess how much time they spent preparing for the class and their attitudes.

\section{Design and Procedure}

All five faculty members signed informed consent statements allowing research data from their courses to be used. For each of the five instructors, one section of their introductory course was assigned to the clicker condition, and the other was assigned to the control condition. All other elements of the course were held constant including testing, assignments, readings, and material covered. Clickers were used during class sessions. Questions varied from opinion questions to reading checks to questions designed to create discussion or check students' conceptual understanding of topics being covered. All questions asked were formative; that is, no question was used as a summative, graded part of the class. Students responded using the clickers and then the material was reviewed as needed. At the end of the semester, all students were asked to complete a course survey designed to measure study habits and attitudes toward the class. All students were informed of the nature of the study and signed informed consent forms.

\section{Results}

The primary dependent variables in this study were student attrition and final class grades. Additionally, faculty and student comments about the class, collected with the end-of-course survey for the students, were also assessed. These comments were submitted on standardized end-of-course evaluation forms.

InSight: A Journal of Scholarly Teaching 
In the clicker classes, $24.66 \%$ of students failed to complete the course, compared to $15.33 \%$ of students who failed to complete the control classes (see Table 2). Chi square analysis revealed that this difference was not significant. Grade distributions also varied between the clicker and control classes, although Chi square analysis revealed that these differences were not significant. As can be seen in Table 3, students in the clicker classes earned more Cs and Fs than students in the control classes. Likewise, students in the control classes earned more As and Bs. The percentage of students earning Ds was identical in both the control and clicker classes.

Table 2: Attrition in Control and Clicker Classes

\begin{tabular}{|l|c|c|c|}
\hline & Enrollment & Completion & $\begin{array}{c}\text { Attrition } \\
\text { Rate }\end{array}$ \\
\hline Clicker & 146 & 110 & $24.66 \%$ \\
\hline Control & 150 & 127 & $15.33 \%$ \\
\hline
\end{tabular}

Table 3: Percentage of Final Grades in Control and Clicker Classes

\begin{tabular}{|l|c|c|c|c|c|}
\hline & $\mathrm{A}$ & $\mathrm{B}$ & $\mathrm{C}$ & $\mathrm{D}$ & $\mathrm{F}$ \\
\hline Clicker & $30 \%$ & $26 \%$ & $25 \%$ & $8 \%$ & $11 \%$ \\
\hline Control & $35 \%$ & $28 \%$ & $21 \%$ & $8 \%$ & $8 \%$ \\
\hline
\end{tabular}

Questions from the end-of-course evaluations did not reveal any apparent differences between the clicker and control classes. Many students also provided written comments about the clicker class on the end-of-the course evaluations with $70 \%$ of those students responding reporting that they enjoyed using the clickers. In addition, $42 \%$ of students reported that they enjoyed the anonymity of the clickers. The remaining students were less positive, reporting that they did not like having to pay for the clickers $(65 \%)$ or that the clickers seemed to interfere with discussion in the classroom (74\%).

Faculty comments revealed both positive and negative aspects of the use of clickers. On the positive side, all faculty reported that they enjoyed using the clickers and believed that students enjoyed the clickers as well. Two negative comments were reported. First, the clickers required more time both in preparing for the class and in conducting the class. When teaching clicker classes, faculty reported spending an average of 2.6 hours more per week preparing for class than when they taught the control classes. Within the class, three of the five faculty reported they had difficulty covering the same material as in the control classes due to the increased time required for students to use their clickers. A second negative comment, from three of the five instructors, concerned what they labeled the 'camaraderie of dissent.' According to these three instructors, clickers allowed students to see how many of them did not understand the material, leading to their rationalization that the material the professor was covering was simply too hard.

\section{Discussion}

In the present study, no significant differences were found in attrition or grades between the clicker and control classes. Attrition rates were higher in the clicker classes, but this difference was not significant. The reason for this is unknown, because students who withdrew obviously did not complete the end-of-course evaluation. Perhaps these students left because they disliked having to purchase or use the clickers. Neither were there significant differences in grade distributions across the two types of classes. This is of concern, as one

In the present study, no significant differences were found in attrition or grades between the clicker and control classes. 
argument for asking students to purchase clickers is that their use is thought to improve student learning. This did not occur in the present study.

Several factors in the present study may have led to these results and may provide the basis for recommendations on the best use of clicker technology. First, in many universities, clickers are being used in large introductory sections of classes. In these classes, faculty interaction with students may be limited due to the sheer number of students and the necessity for the professor to cover a large amount of material. In such classes, students may be able to skip class or attend but never say a word, so the use of clickers guarantee at least some level of participation. In smaller classes, such as the ones in the present study, students are more likely to already have significant interaction with the professors. In fact, several students in the present study reported that they disliked the clickers because they interfered with the type of interaction they were accustomed to with their professors. These results are consistent with those of Carnaghan and Webb (2007), who also found a decline in student engagement with the introduction of clickers. As a result, one recommendation might be to only use clickers in large classes where more personal means of interaction might be problematic.

A second issue concerns the familiarity of the faculty member with the use of clickers and the manner in which the faculty member incorporates clickers into the classroom. The first time a faculty member uses a new form of technology or introduces any new component into a course, there may be awkwardness leading to increased problems and less chance of success (Draper \& Brown, 2004). In the present study, this was the first time the instructors had utilized clickers in the classroom. It is certainly possible that with continued use, clicker classes would show the expected improvements in learning suggested by the literature. This may not be a strong explanation in the present study, however, because all five instructors went through a clicker training process aimed to both reduce any awkwardness in use, and ensure that questions created for use with the clickers would be best suited for student engagement and learning. In fact, the fifth instructor continued to use the clickers for two additional semesters and continued to collect data. The results in her subsequent classes matched the results during the original semester. Whether faculty using clickers in other locations receive such training prior to using this technology is questionable. To ensure success with clickers, it seems likely that professors need specific training in the use of the technology and in writing appropriate questions for use with the clickers. Questions of most use might be those designed to enhance discussion and those that probe for more conceptual or applied understanding on the part of students. For example, research has noted the probable benefits of clickers when used to facilitate students' "interactive engagement" with the material, the instructor, and each other (Brewer, 2004; Draper \& Brown, 2004; Judson \& Sawada, 2002).

Finally, in the present study, clickers were only used for formative purposes. No grades were attached to students' responses to clicker questions. It seems reasonable to expect differences to appear when faculty use formative vs. summative questions. It is possible that if the instructors in the present study had combined formative and summative clicker questions, the students would have valued this aspect of the class more and students in the clicker sections would have performed better in the class. This question would be an interesting one for future research.

From a broader perspective, this research led our campus to several decisions. While not prevented from utilizing clickers in their classroom if they so chose, faculty were encouraged to consider the results of the present study and to attend the training provided by the teaching and learning center. Four of the five instructors in the study decided not to use clickers in the future. As mentioned earlier, the fifth instructor continued with the clickers for two additional semesters,

InSight: A Journal of Scholarly Teaching

Using a cross-campus approach to designing and conducting research on clicker effectiveness allowed for the inclusion of faculty who might never have considered conducting such research on their own. 
but due to continuing poor results, has now discontinued their use. Using a crosscampus approach to designing and conducting research on clicker effectiveness allowed for the inclusion of faculty who might never have considered conducting such research on their own. In addition, this model has been adopted by our campus for assessing the effectiveness of other forms of pedagogical technology, prior to their widespread introduction across the campus.

\section{References}

Bransford, J., Brophy, S., \& Williams, S. (2000). When computer technologies meet the learning sciences: Issues and opportunities. Journal of Applied Developmental Psychology, 21(1), 59-84.

Brewer, C. A. (2004). Near real-time assessment of student learning and understanding in biology courses. Bioscience, 54(11), 1034-1039.

Brickman, P. (2006). The case of the Druid Dracula. Journal of College Science Teaching, 36(2), 48-53.

Collins, L.J., Moore, M.E., \& ShawKokot, J. (2007). Livening up the classroom: Using audience response systems to promote active learning. Medical Reference Services Quarterly, 26(1), 81-88.

Draper, S. W., \& Brown, M. I. (2004). Increasing interactivity in lectures using an electronic voting system. Journal of Computer Assisted Learning, 20(2), 81-94.
Judson, E., \& Sawada, D. (2002). Learning from past and present: Electronic response systems in college lecture halls. Journal of Computers in Mathematics and Science Teaching, 21(2), 167-181.

MacGeorge, E., Homan, S., Dunning, J., Elmore, D., Bodie, G., Evans, E., Khichadia, S., Lichti, S., Feng, B., \& Geddes, B. (2008). Student evaluation of audience response technology in large lecture classes. Educational Technology Research \& Development, 56(2), 125-145.

Morling, B., McAuliffe, M, Cohen, L., \& DiLorenzo, T.M. (2008). Efficacy of personal response systems ("clickers") in large, introductory psychology classes. Teaching of Psychology, 35(1), 45-50.

Stowell, J.R., \& Nelson, J.M. (2007). Benefits of electronic audience response systems on student participation, learning, and emotion. Teaching of Psychology, 34(4), 253258.

Trees, A.R., \& Jackson, M.H. (2007). The learning environment in clicker classrooms: Student processes of learning and involvement in large university-level courses using student response systems. Media \& Technology, 32(1), 21-4

Robin Morgan, PhD, has taught at Indiana University Southeast since 1988. She has won numerous teaching awards, served as the founding director of her campus teaching and learning center, and developed the peer review training process for her campus. Her current research examines student stalking of faculty and its impact on teaching. 